\title{
Festividade e territorialidades na parada LGBT goianiense
}

\section{Festivity and territorialities in Goiânia's LGBT parade}

\author{
Carlos Eduardo Santos Maia \\ carlmaia@uol.com.br \\ Universidade Federal de Juiz de Fora
}

\begin{abstract}
Resumo: As paradas LGBTs têm se constituído numa grande festa popular nas cidades onde são realizadas. Neste artigo, analisamos algumas questões referentes à festividade e às territorialidades na parada LGBT goianiense, o contexto de festa e não-festa, o confronto com a ordem, a superação e ratificações de visões de mundo. Abordamos ainda sua composição espacial, estratégias de controle exercidas em seu espaço e certos modos como as territorialidades são produzidas. Em termos metodológicos, nossas análises são orientadas por participações, observações e entrevistas realizadas na Parada goianiense, embora, sempre que possível, recorramos a outros contextos a título de exemplo.
\end{abstract}

Palavras-chave: Parada do orgulho LGBT. Festa popular. Festa e gênero. Festa urbana. Goiânia/GO.

Abstract: LGBT parades have been constituted as a great popular festival in the cities where they are held. This article examines some issues concerning the festivity and territorialities in Goiania's LGBT parade, the contexts of party and non-party, confrontation with the order, overcoming and ratification of worldviews. It also explains the spatial composition of the parade, strategies to control access within its space, and ways in which the territorialities are produced. Methodologically, our analysis is guided by participation, observations and interviews regarding Goiânia's parade, although, whenever possible, we make use of other contexts for further example.

Keywords: LGBT Pride Parade. Popular party. Party and gender. Urban party. Goiânia.

Resumen: Las Paradas LGBT han constituido una gran fiesta popular en las ciudades donde se celebran. En este trabajo, se analizan algunas cuestiones relativas a la festividad y las territorialidades en la parada LGBT Goianiense en el contexto de fiesta y no fiesta, la confrontación con el orden, las uperación y las ratificaciones de las visiones del mundo. Se discute también su composición espacial, las estrategias de control ejercidas en su espacio y ciertos modos de producción de las territorialidades. En términos metodológicos, nuestros análisis fueran guiados por las participaciones, observaciones y entrevistas en la Parada de Goiânia, aunque, siempre que se ha posible, recurramos a otros contextos con el fin de ejemplificar.

Palabras claves Parada delorgulloLGTB. Fiesta Popular. Fiesta ygénero. Fiesta urbana. Goiânia/GO 


\section{INTRODUÇÃO}

As paradas LGBTs têm atraído paulatinamente maior quantidade de público nas cidades em que se realizam, tornando-se mesmo um grande evento turístico em determinados locais, como São Paulo (SP) e Juiz de Fora (MG). Porém, em outras cidades, forças políticas conservadoras ainda dificultam ou não apoiam a festa, talvez pelas "inversões e perversões" que vogam na sua ocorrência aos olhos dos "caretas"1 empedernidos.

Neste trabalho, discutimos a festa da parada LGBT tomando como contraponto inicialmente o contexto da antifesta e de restrições à homossexualidade estabelecidas na cultura judaico-cristã. A partir daí, apresentamos algumas reflexões sobre a diversidade que a parada instaura na cidade, considerando o caso da festa goianiense, e as territorialidades constituídas, ainda que fugazes.

Expomos também como a composição espacial da festa implica o estabelecimento dessas territorialidades em que se destacam como elementos axiais os trios elétricos e o próprio corpo, daí as nossas considerações, mesmo que sucintas, acerca de como os corpos-sujeitos interagem.

Em termos de composição-redação procuramos, neste texto, à maneira de como David Bell discorre sobre o seu trabalho Screwing Geography/fucking geography, "ser um pouco ofensivo ou controverso, como uma forma de agitar as coisas" e "pensar sobre o que podemos e não podemos dizer em geografia" (2010, p. 318), ou na ciência de maneira geral, que se utiliza, frequentemente, de uma linguagem asséptica, pasteurizada e distante daqueles atores que são utilizados como fonte de informação e, provavelmente, se forem apresentados aos textos produzidos com esta linguagem não se reconhecerão como informantes.

Metodologicamente, recorremos a um embasamento teórico resgatando textos clássicos que versam sobre festa popular, procurando alimentá-los com nossas observações recentes na festa de Goiânia. Artigos e postagens na internet são também expedientes que utilizamos em nossas referências. Em relação às observações, iniciaram-se na parada de Goiânia no ano de 2004 e nos anos de 2010 e 2011, realizamos entrevistas estruturadas com os participantes, sendo alguns dados apresentados neste artigo.

\section{FESTA E ANTIFESTA}

Girard, em sua clássica obra A Violência e o Sagrado, compreende a festa, em parte, orientado pela perspectiva durkheimiana como rito que vivifica e renova a ordem cultural, complementando que ela (1990, p. 154) “é apenas uma preparação para o sacrifício, que marca seu paroxismo e simultaneamente sua conclusão". Na sua concepção, o sacrifício, ou melhor, a crise sacrificial acompanha mesmo as festas desagregadas do pensamento religioso e "desritualizadas", por isso, tanto nestas ("desritualizadas"), quanto

1 "Careta", conforme define Houaiss, em sentido figurado, significa conservadorismo, preso a convenções, quadrado e tradicionalista (http://houaiss.uol.com.br). 
naquelas (ritos que repetem a experiência fundadora), tem-se (p. 380) “a feliz comemoração de uma crise sacrificial parcialmente transfigurada". Ressalte-se que o autor define a crise sacrificial (1990, p. 67) "como uma 'crise das diferenças', ou seja, da ordem cultural em seu conjunto", crise esta que o rito procura evitar. Porém, em sendo a festa uma comemoração da crise sacrificial, conforme observamos, (p. 155) "a própria crise torna-se objeto de prazer", perpassando nesta "feliz comemoração" dois vetores fundamentais de desordem intimamente relacionados, quais sejam, a sexualidade e a violência:

a sexualidade alia-se frequentemente à violência, seja em suas manifestações imediatas (...) seja em suas mais longínquas consequências (...) A sexualidade provoca inúmeras desavenças, ciúmes, rancores e lutas; é uma ocasião permanente de desordem, mesmo nas mais harmoniosas comunidades.

... Assim como a violência, o desejo sexual assemelha-se a uma energia que se acumula e que acaba por causar mil transtornos se for contida por um tempo demasiadamente longo. Por outro lado, deve-se observar que o deslizamento da violência para a sexualidade e da sexualidade para a violência ocorre com muita facilidade, tanto em um sentido quanto em outro, mesmo nas pessoas "normais", e sem que seja preciso invocar a menor "perversão". (GIRARD, 1990, p. 51).

Se a festa, como afirma Girard, traz à baila a (1990, p. 153) "diferença abolida ou invertida", com "reuniões antinaturais e os mais imprevistos encontros", nos quais "as desordens e a contestação grassam por toda parte", as sociedades também produzem a "antifesta", momento em que há (p. 155) "precauções extraordinárias para evitar a recaída na violência recíproca", procedendo-se "um período de austeridade extrema". Girard sugere ainda, além da festa e da antifesta, a existência de (1990, p. 157) "exemplos 'mistos'" entre a obrigação da transgressão e sua proibição, "entre a crise e a instauração da ordem", cuja "interpretação leva em conta tanto a continuidade quanto a descontinuidade". Mas em seu texto, isso fica apenas como ideia, que aqui tomamos como ponto de partida para analisar a festividade e as territorialidades na parada LGBT goianiense.

Sugere-se aqui, inicialmente, que na nossa cultura judaico-cristã, bem como em outros sistemas simbólicos religiosos, a homossexualidade é amiúde condenada e interpretada pela ideia de pecado, bem como os homossexuais rotulados de pecadores. Determinados líderes e praticantes do catolicismo e do protestantismo, por exemplo, recorrem a certas passagens bíblicas ${ }^{2}$ para fazer tal julgamento, especialmente em Gênesis 1:27 e 19:1-13; Levítico 18:22, 20:13; Romanos 1:24-32; II Coríntios 5:17 e I Coríntios 6:10, sentenciando-se nesta última que: "Não erreis: nem os devassos, nem os idólatras, nem os adúlteros, nem os efeminados, nem os sodomitas, nem os ladrões, nem os avarentos, nem os bêbados, nem os maldizentes, nem os roubadores herdarão o reino de Deus".

É comum ouvirmos padres e pastores afirmarem em suas pregações que não aceitam o "homossexualismo" (termo que até hoje costumam empregar), porém os homossexuais são bem-vindos em suas igrejas, se quiserem se libertar. Numa das

2 Disponível em: <http://www.bibliaonline.com.br> Acesso em: 8 fev. 2012. 
igrejas neopentecostais que têm recebido grande quantidade de fiéis atualmente, a Igreja Universal do Reino de Deus, fazem-se "trabalhos de libertação" de homossexuais, retirando-se supostas "entidades" que se apoderam do seu corpo e os tornam gays. Em vídeo postado na internet, tem-se um caso $^{3}$ em que a autoridade máxima dessa "igreja" comanda uma sessão de libertação de "bruxarias" feitas num homossexual que, ao final, diz ter-se tornado heterossexual, já que foram "queimadas" todas as entidades que o aprisionavam.

Não se pode negar que na sociedade brasileira, o ideário cristão oriente nosso sistema de valores e representações sobre sexualidade, família, casamento etc, de modo que "precauções" contra a homossexualidade sejam reafirmadas no cotidiano, salientando o contexto de antifesta, encenada exemplarmente no vídeo mencionado. Essas "austeridades extremas" nos fornecem um viés para interpretamos a existência cotidiana "dentro do armário" 4 de grande parte dos homossexuais. Todavia, situações mistas de festa e antifesta perpassam o cotidiano nos redutos gays, como bares, boates e saunas, espaços privados em que se materializam a coexistência entre a obrigação da transgressão (de se mostrar como gay) e sua proibição (assumindo a condição de gay somente entre os pares que estão ali presentes).

Vejamos agora o contexto em que a "desordem" se instaura e vem à tona nos espaços públicos, quer dizer, na festa da parada LGBT, particularmente a que temos acompanhado na Cidade de Goiânia.

\section{FESTA E (É) DESORDEM?}

A parada LGBT goianiense, no ano de 2011, segundo informações do cartaz de divulgação, teve a sua décima quinta edição. Acompanhamos esta festa, pela primeira vez, no ano de 2004, quando se noticiou a ocorrência da Segunda Parada do Orgulho Gay ${ }^{5}$. Como não é objetivo deste texto entrar na celeuma de quando se realizou efetivamente a primeira parada em Goiânia, destacamos que, no período que acompanhamos a festa, a partir de 2004, notamos um aliciamento progressivo de alas religiosas, sendo inclusive determinada igreja (Igreja Iris - Igreja Renovada Inclusiva para a Salvação) participante da comissão organizadora em suas últimas edições. No ano de 2010, o contrato de locação dos "trios elétricos" da parada, por exemplo, foi elaborado pelo pastor presidente da referida Igreja ${ }^{6}$. Ainda no ano de 2010, tivemos participando da parada a Igreja Anglicana (Figura 1).

3 O referido vídeo pode ser assistido no seguinte endereço: <http://www.youtube.com/watch?v=fRKsAv51gd8> Acesso em: 8 fev. 2012.

4 Costuma-se usar esta expressão para definir a homossexualidade oculta, deliberadamente ou não.

5 Disponível em: <http://www.aids.gov.br>, <http://www.midiaindependente.org> Acesso em: 12 fev. 2012.

6 Disponível em: <http:// paradagoias.blogspot.com> Acesso em: 14 abr. 2010. 
Figura 1 - Faixa indicativa do apoio da Igreja Anglicana à parada LGBT goianiense

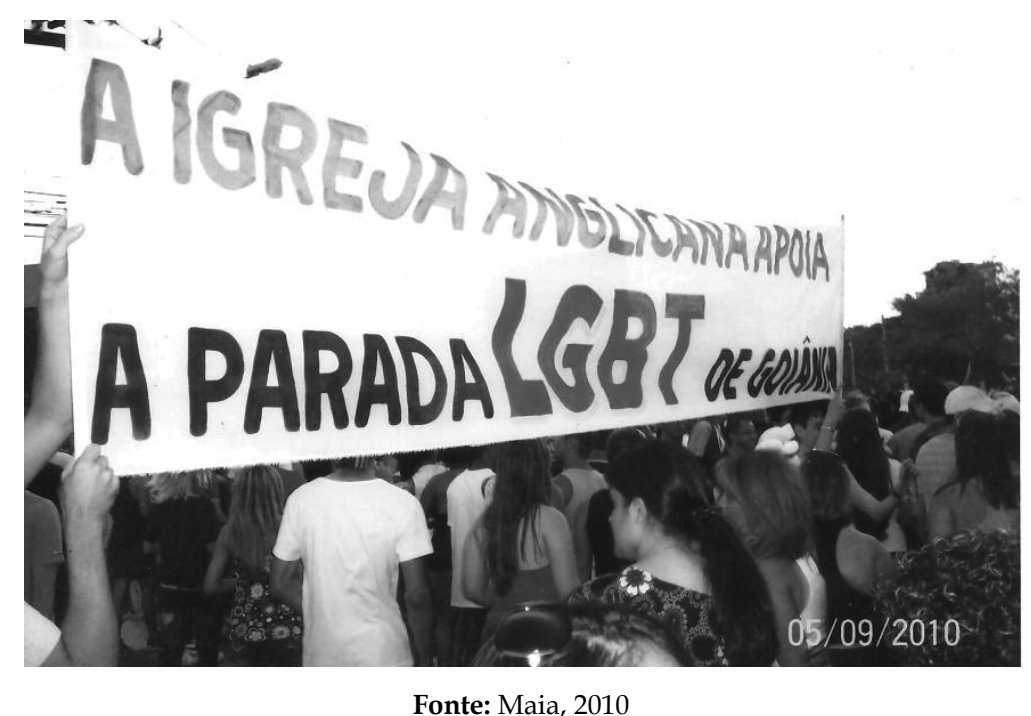

Já no ano anterior, houve um casamento gay celebrado durante a festa, com direito a todas as tradições religiosas como padrinhos, pastor celebrando, troca de alianças, convidados, beijo ao final da cerimônia etc. Isso nos sugere que a parada não se mantém alheia à religião na qualidade de festa, seja para resgatar seus princípios e dogmas (como o casamento), seja para criticá-la. Em relação a isso, dois microterritórios podem ser observados nas paradas: um dos religiosos "progressistas" aliados dos direitos do LGBTs, que levam faixas e cartazes para marcar a sua presença, outro dos participantes que criticam as alas conservadoras das Igrejas proferindo discursos, empunhando faixas e cartazes; ou fantasiados de padres, papas, freiras etc. como nota Campos (2006). Essa proximidade crescente da parada com Igrejas poderia inclusive indicar que, de uma situação de festa, esta comece a ser um daqueles exemplos mistos entre a transgressão e a proibição aventados por Girard (1990), mas isso merece ser mais bem investigado.

Um aspecto relevante em relação às territorialidades da "desordem" na parada é a sua ritualidade, pois, em seu conjunto, os rituais da parada intensificam a "diferença abolida ou invertida". Desse modo, permite-se a "saída do armário", a exibição pública da homoafetividade e mesmo do homoerotismo, além do uso de roupas íntimas (cuecas) à vista (Figura 2), a feminilidade no "masculino", a masculinidade no "feminino" e as mais diversas nuances de identidade de gênero, tudo isso carregado de conteúdo emocional e produzindo interações espaciais. 
Figura 2 - Hedonismo e erotismo.

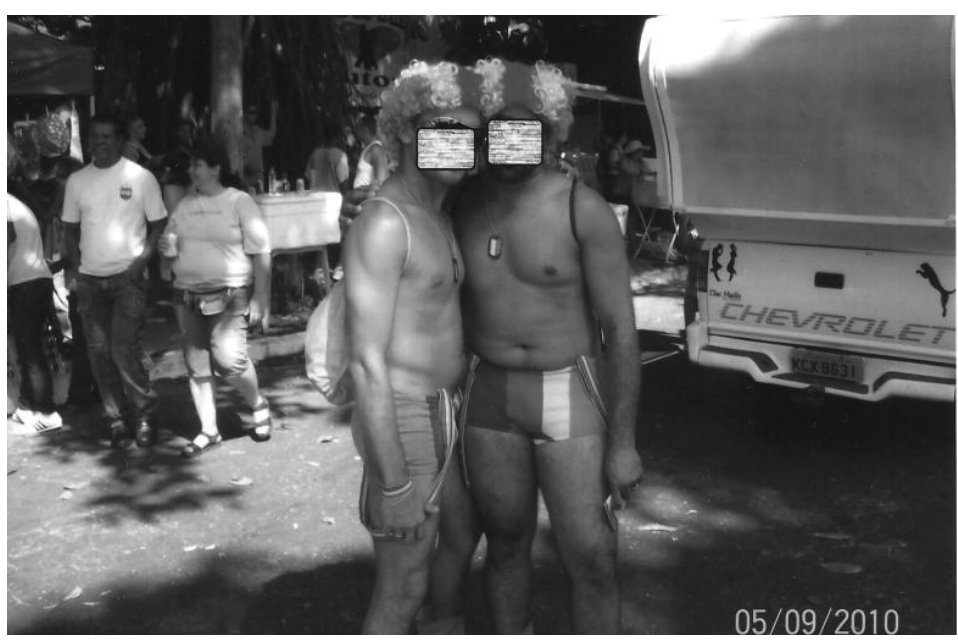

Fonte: Maia, 2010

No cenário emoldurado pelo arco-íris, reconhecido pelos entrevistados como o principal símbolo da parada, demarcando assim o território próprio da festa, manifestam-se a "efervescência" e os "excessos" mencionados por Durkheim (1989), que revelam comportamentos afetivo-sexuais ignorados, coibidos e/ou recriminados costumeiramente na sociedade heteronormativa. A efervescência é provocativa, pois "desordena" enquanto reúne ampla diversidade de atores LGBTs ou não. Aliás, o segundo maior público participante da parada declarou-se heterossexual nas entrevistas que realizamos (Figuras 3 e 4), sendo comum os heterossexuais masculinos se exibirem como "pegadores e comedores de mulheres", tornando-se por isso mesmo cobiçados por alguns gays que valorizam esta demonstração de virilidade na festa. Já os excessos não são um epifenômeno da parada, mas decisivos na sua realização. Os excessos dão visibilidade aos participantes; retirando-os de guetos e constituindo temporariamente o Centro da cidade como palco do "orgulho". 
Figura 3 - Orientação sexual (Goiânia - 2010)

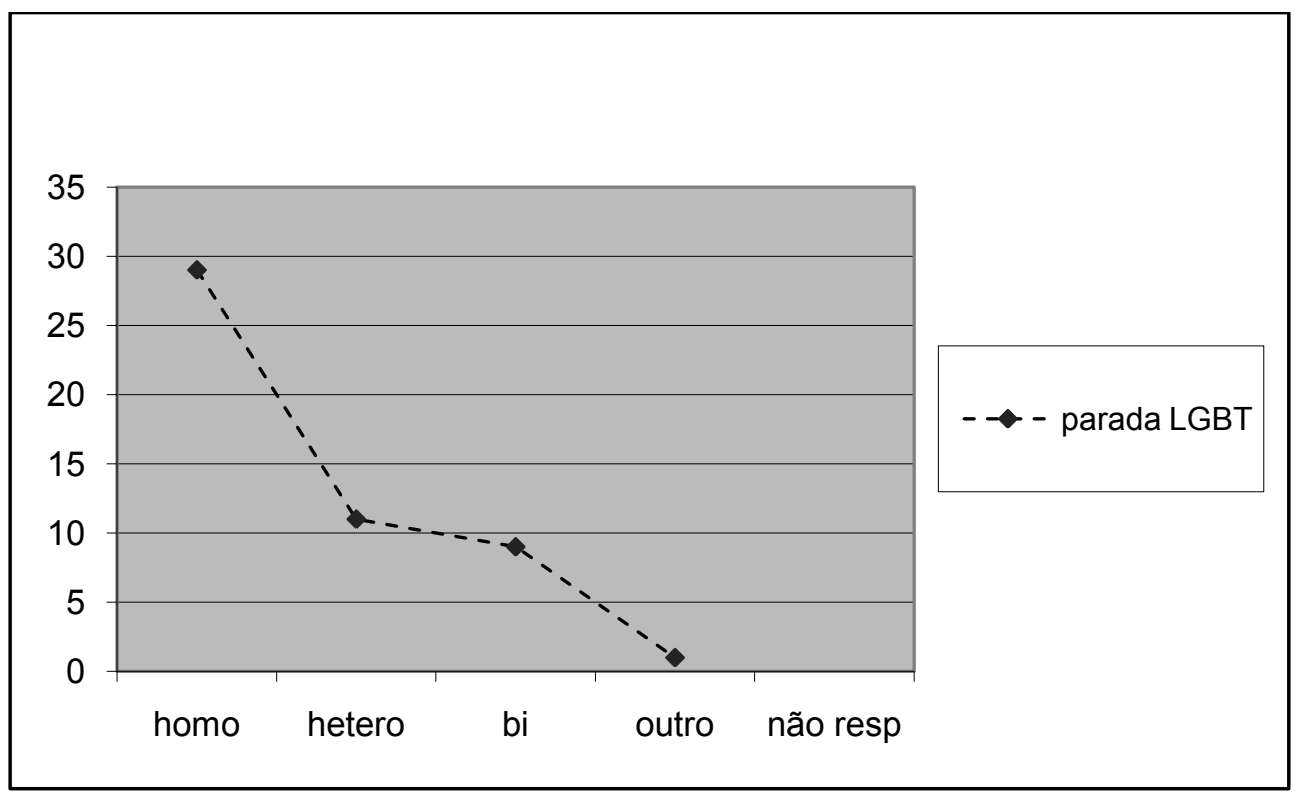

Figura 4 - Orientação sexual (Goiânia - 2011)

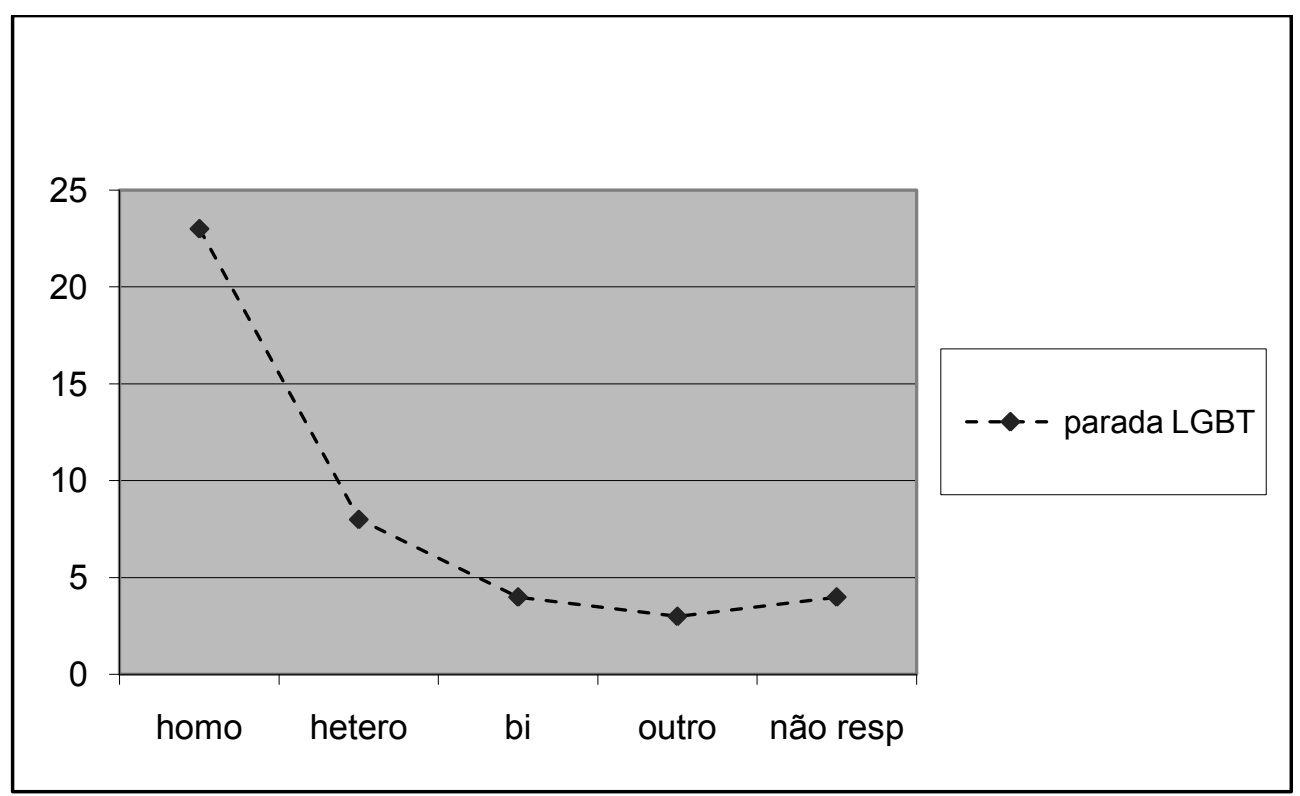

Fonte: Maia, 2011

\section{A COMPOSIÇÃO ESPACIAL}

A parada LGBT goianiense, como ocorre nas demais que tivemos a oportunidade de acompanhar, possui três espaços que constituem o substrato para as territorialidades produzidas: concentração, percurso e dispersão. Nos anos que acompanhamos a sua ocorrência, de 2004 a 2011, esses três espaços foram alterados. Assim, de 2004 a 2010, a concentração e a dispersão ocorreram em frente ao Bosque Botafogo, e o percurso seguia 
pelas Avenidas Paranaíba, Tocantins e Araguaia (Figura 5). Já no ano de 2011, em virtude de uma obra na área do Parque Mutirama (parque infantil) e do Bosque Botafogo, a concentração deu-se na Praça Cívica, seguindo-se o percurso pelas Avenidas Araguaia, Paranaíba e Tocantins, onde houve a dispersão nas proximidades, novamente, da Praça Cívica.

Figura 5 - Planta do Percurso da Parada de Goiânia no Ano de 2010

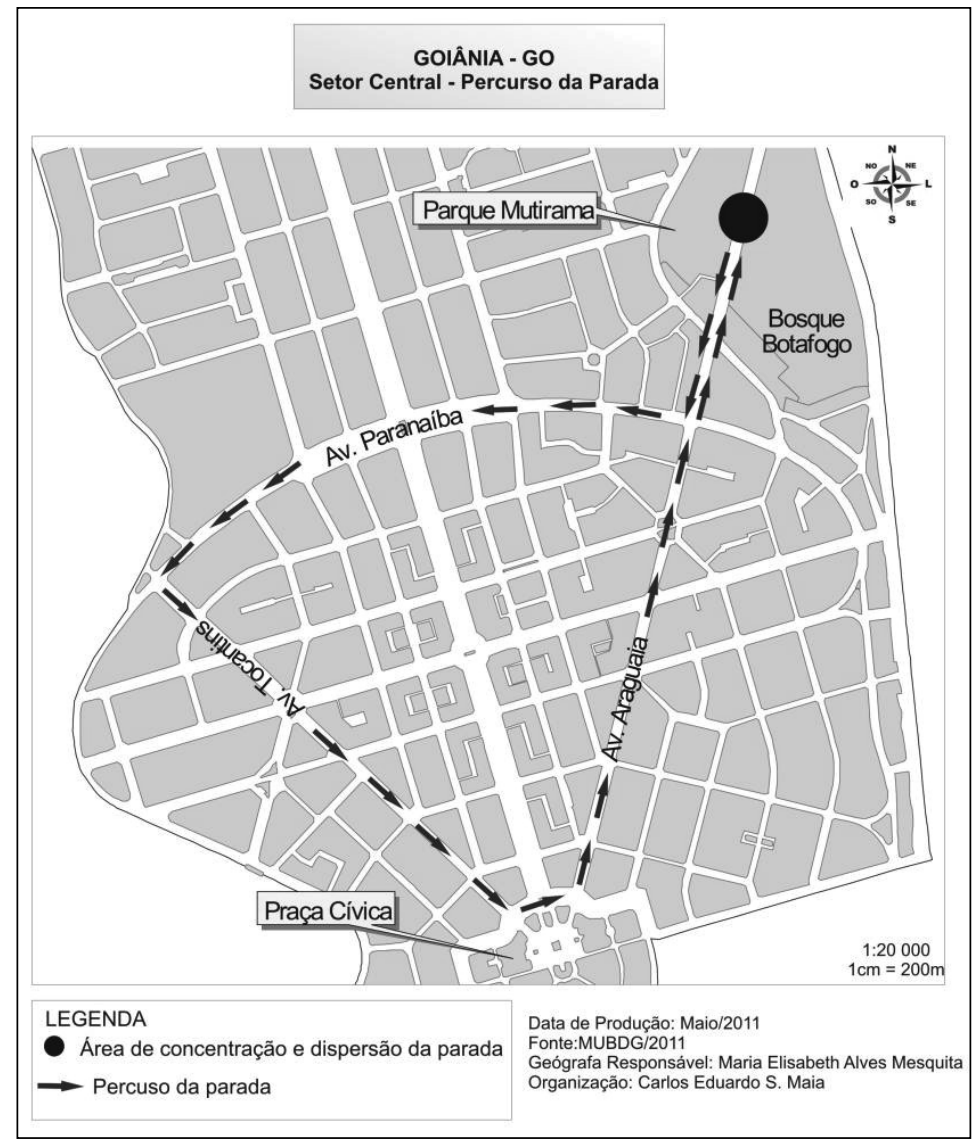

O Bosque Botafogo era uma área conhecia pela "pegação" e, durante a parada, vários participantes adentravam no bosque a fim disso. Note-se que "pegação" é aqui entendida como "prática de encontros sexuais de maneira anônima em locais públicos (parques, bosques, praias, banheiros públicos etc.) ou ainda em espaços privados (saunas, cinemas, boates, darkrooms etc.)" (MELO, 2009). Desse modo, a concentração da parada acabava ratificando a centralidade deste point $t^{7}$ gay de "pegação", além de outro, uma sauna frequentada também por gays que existia em frente ao bosque (sauna esta demolida para as obras de reforma do parque). No ano de 2011, como a área de concentração foi a

7 Expressão popular para definir um lugar central. 
Praça Cívica, a "pegação" foi menor, pois não havia locais que a favorecessem. A Praça Cívica deu mais visibilidade à parada, pois a Rua 82 que a contorna é um eixo de circulação bem movimentado, mesmo aos domingos.

Na área de concentração da parada, nota-se ainda a presença de camelôs e ambulantes que vendem adereços nas cores do arco-íris, comidas (churrasquinhos) e principalmente bebidas. Na entrada do Parque Mutirama construía-se um palco onde, nos anos de 2009 e 2010, observamos, na véspera, à noite, um concurso de drag queen que faz parte dos preparativos da parada, concurso este que em edições anteriores foi realizado noutros lugares (boates e na Rua 8, no Centro da Cidade, conhecida também como rua do lazer) e, no ano de 2011, ocorreu no Centro Cultural Martim Cererê. Durante o dia da parada, o palco servia para as entidades organizadoras se pronunciarem acerca da luta e dos direitos LGBTs, recebimento de convidados, declaração de discursos e outras palavras de ordem, shows e, entre uma e outra dessas atividades, DJs tocavam a indefectível dance music em suas versões de house music, techno e trance, principalmente. Neste palco também realizou-se um casamento gay, na parada de 2009.

O público começa a chegar à concentração principalmente a partir das 14 horas, mas os camelôs chegam mais cedo, por volta das 8-9 horas, para "marcarem seu ponto" e armarem as barracas, demarcando na festa territorialidades de comerciais com produtos necessários e procurados na festa. Os trios elétricos chegam à concentração por volta das 10 horas e são decorados com bolas de gás e outros enfeites nas cores do arco-íris. Por volta das 13 horas, começam a tocar a música (dance) em som altíssimo, o que serve de convite para que as pessoas se aglomerem. Aliás, grande parte dos participantes fica em torno dos trios elétricos dançando, paquerando, "dando pinta" ${ }^{8} \mathrm{e}$ alguns se destacam por terem o direito de subir nos trios como convidados ou pagantes.

Antes da saída, ainda na concentração, canta-se o hino nacional e, a seguir, é dado o comando para os trios elétricos seguirem pelas ruas. O canto do hino nacional procura ressaltar a dimensão cívica existente nesta territorialidade festiva, mas nem todos os participantes o acompanham segundo as normas estabelecidas, ou prestam atenção à sua execução, ou mesmo se preocupam com esta dimensão da festa. O percurso não é muito extenso, como nota-se no mapa, e segue pelo centro comercial-administrativo de Goiânia, geralmente vazio aos domingos. Mas nos poucos prédios residenciais que aí existem, os moradores abrem a janela e espiam os passantes, alguns dançando ao ritmo da música, outros com olhar de reprovação. Nos cruzamentos da Av. Paranaíba com a Av. Goiás, Av. Anhanguera com Av. Tocantins, e Av. Araguaia com Av. Goiás a parada provoca um relativo congestionamento no trânsito, que é interditado para a sua passagem. Porém, o seu espaço-tempo de ocorrência (centro comercial-administrativo e proximidade do feriado de 7 de setembro) contribui para que este congestionamento não assuma grandes dimensões. Uma pausa no som altíssimo é dada quando a parada aproxima-se do cruzamento da Rua Paranaíba com a Rua 20 até a 20a devido à presença de hospitais.

8 "Dar pinta", na linguagem gay, significa mostrar intencional e exageradamente sua homossexualidade, em geral, mediante gestos, modo de falar e de exibir-se em público. Às vezes, utiliza-se também como sinônimo a expressão "dar pala". 
O percurso é seguido pelos participantes que estavam na concentração e não se veem muitas pessoas ingressando ao longo do trajeto. Evidentemente, ambulantes que vendem bebidas também acompanham a parada e chegam à dispersão com os isopores vazios, pois setembro, mês de ocorrência da festa, é bastante seco em Goiânia o que, aliado ao "clima próprio da parada", estimula o consumo exagerado de bebida. O percurso da parada concretiza aqueles trajetos definidos por Magnani (2009), ou seja, "percursos determinados por regras de compatibilidades - que abrem o particularismo do pedaço a novas experiências, situadas fora das fronteiras daquele espaço conhecido, onde se está protegido por regras claras e inequívocas de pertencimento". No deslocamento pelas ruas centrais, a parada agrupa ao mesmo tempo separa os atores envolvidos; os iguala nas intenções de mudança social e garantia de direitos e mostra as diferenças de identidade de gênero, de orientação sexual e de realização afetiva; retira-os do "armário", das boates e saunas e os mostra como cidadãos.

A chegada à dispersão é marcada pelo fim da música. Cada trio elétrico desliga a sua aparelhagem e o som da dance music é substituído pelo vozerio. Em uma das edições que acompanhamos, no ano de 2009, lamentavelmente o som dos trios elétricos deu lugar às sirenes da Polícia Militar de Goiás, que expulsou os participantes usando cassetetes, spray de pimenta e inclusive as suas viaturas eram direcionadas propositalmente no rumo dos que ainda estavam nas ruas, ameaçando-os de atropelamento. Pouco a pouco os participantes tomaram o caminho de casa, porém os mais animados seguiram para uma boate ou bar gay, ou seja, a noite cai e regressam aos "armários" ou aos guetos, pois a festa acabou e a crise das diferenças parece extenuar-se, até que seja vivificada no ano seguinte.

\section{ALGUNS COMENTÁRIOS SOBRE AS TERRITORIALIDADES}

Embora a cidade seja diversidade e, como já proferia Aristóteles (1997, p. 28), “a cidade não se compõe apenas de indivíduos reunidos em maior ou menor número, ela se forma ainda de homens especificamente diferentes", a diferença e a diversidade LGBT só são aceitas se encaixadas (encaixotadas) em padrões heteronormativos, principalmente no tocante às manifestações homoafetivas em público. $\mathrm{O}$ encaixotamento em padrões heteronormativos, além de concepções arcaicas de moral, revela como se produzem territórios excludentes na cidade, apesar/em virtude da sua diversidade.

Comecemos nossas incursões neste assunto a partir da seguinte observação de Sack: "Território pode ser usado não apenas para conter ou restringir, mas também para excluir" (2011, p. 78). Cotidianamente, a população LGBT sabe muito bem o que isso significa: demonstrar afetividade a outro(a) do mesmo sexo pode resvalar em constrangimento e mesmo expulsão de certos lugares, ainda que estes tenham acesso público, já que isso é considerado como "ato libidinoso, imoral, indecente" etc. segundo aqueles que consideram como "normal" (e moralmente aceito) apenas relacionamentos/afetividades heterossexuais - os quais podem mostrar publicamente seu afeto ao (à) parceiro(a). 
A intolerância às cenas de homoafetividade tem gerado protestos à maneira de "beijaços" ${ }^{\text {, }}$ geralmente organizados por ONGs que defendem os direitos LGBTs e combatem a intolerância e a violência sofrida pelos(as) cidadãos(ãs) homossexuais. Esta forma de protestar contra a homofobia ganhou notoriedade principalmente a partir de 2003, quando, no Shopping Frei Caneca, em São Paulo, um casal gay, à época com 21 e 25 anos de idade, foi repreendido por um segurança por ter se beijado no saguão de entrada do shopping ${ }^{10}$. Como forma de expressão de desacordo, a "comunidade" LGBT organizou o "beijaço" na praça de alimentação, reunindo cerca de dois mil participantes. Atualmente, é comum observamos neste shopping casais gays abraçados, de mãos dadas e "trocando selinhos" (leves beijos na boca) livremente.

A Cidade de Goiânia também já teve o seu "beijaço", realizado no Banana Shopping, em 2006, shopping este que, desde a sua inauguração, é bastante frequentado por gays, entre outros motivos, em virtude da existência de uma sauna para este público em frente a uma de suas entradas. Neste caso, segundo noticiou-se na época, houve inclusive truculência por parte da polícia militar goianiense na repressão aos "beijoqueiros", levando-os a organizar a manifestação:

"Eu beijo João, eu beijo Ana. Pra homofobia, uma banana?". Com essas palavras de ordem, diversos militantes dos direitos homossexuais, além de simpatizantes, chamaram a atenção de quem passava, no final da tarde de ontem, em frente ao Banana Shopping, no centro de Goiânia. Cartazes coloridos e apitos estridentes foram as ferramentas usadas em protesto pacífico contra um episódio que aconteceu no Shopping, na tarde de terça-feira passada. Um grupo de aproximadamente 18 estudantes homossexuais teria sido agredido verbalmente e intimidado por seguranças do local por se beijarem publicamente. "Como alguns casais heterossexuais estavam se beijando, decidimos fazer o mesmo. Não aconteceu nada além disso. Foram beijos normais, de leve", conta a administradora Íris Dantas de Castro, 23, que estava presente durante a confusão com a companheira, Andréia Cordeiro, 24. Segundo Íris, um segurança abordou o grupo dizendo que o shopping não permitia esse tipo de atitude. Em seguida, um administrador do estabelecimento teria chegado ao local com dois policiais militares e dito que o código de posturas do shopping não autoriza esse comportamento. "Um PM deu uma chave de braço num dos nossos amigos. Outro policial me ameaçou. Fiquei com medo", relata Íris ${ }^{11}$.

Em meio a constrangimentos, restrições e exclusões, não é de se admirar que a parada seja um momento em que a diversidade LGBT se exponha e, mais que isso, exiba publicamente seus desejos, sua afetividade, seus sentimentos. Diferentemente de uma parada militar como festa da ordem, em que as diferenças são mantidas, dado que estas são "ritos de reforço", as paradas LGBTs possuem propriedades estruturais dos "ritos de inversão" (DAMATTA, 1998, p. 82), inclusive com a reconfiguração territorial dos

9 Manifestação pública em que o(a)s participantes se propõem a beijar (na boca) parceiros(as) do mesmo sexo.

10 Disponível em: <http://www.aids.gov.br>, <http://www1.folha.uol.com.br>.

11 Disponível em: <http://www.ohoje.com.br> Acesso em: 12 fev. 2012. 
espaços públicos da cidade apropriados pela festa e do que se pode fazer nesse espaço como beijar parceiro(a) do mesmo sexo; demonstrar intenção de casamento, de união estável, de constituir família, de apenas "dar pinta" etc. Aceita-se o que antes era proibido ou, ao menos, tolera-se, disfarçando-se fronteiras sociais e espaciais, conforme se percebe nos dados a seguir acerca da receptividade da cidade aos LGBTs, respeitando a sua cidadania, no dia da festa e fora do dia de festa.

Nota-se nos gráficos (Figuras 6 e 7) que, segundo o(a)s depoentes, nos dias de festas, a aceitação é maior, diferente do que ocorre fora do dia da parada, havendo um sensível aumento do(a)s que afirmam que a cidade não (a)os recebe bem.

Figura 6 - Receptividade da cidade ao público LGBT no dia de festa (2010-2011)

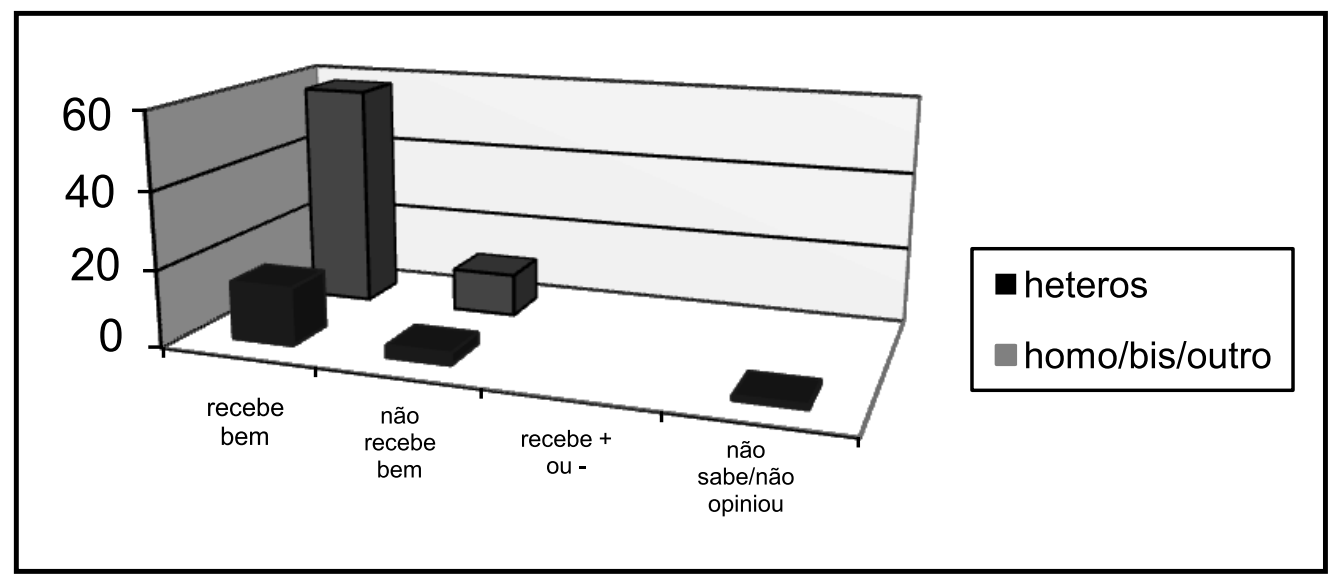

Figura 7 - Receptividade da cidade ao público LGBT fora do dia de festa (2010-2011)

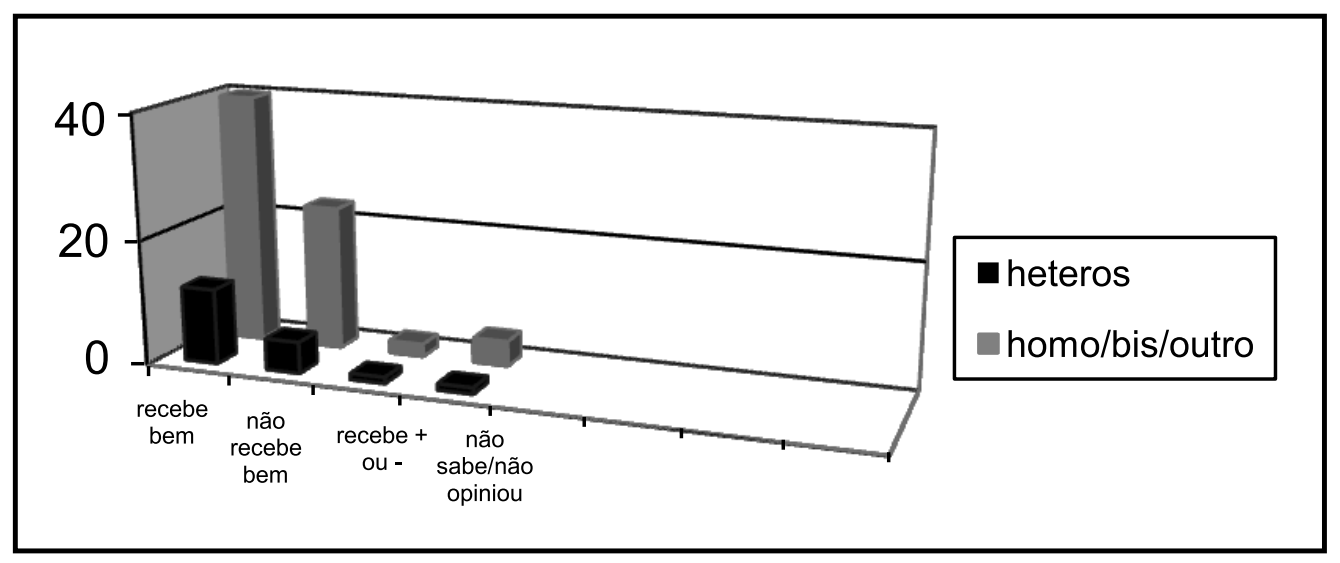

Mas a parada é também um momento de manifestação contra a violência sofrida por gays, travestis, transexuais e lésbicas, principalmente quando estes demonstram publicamente sua orientação sexual. Geralmente ocorrem pronunciamentos antes da parada e cartazes são carregados pelos participantes versando sobre esta temática, defendendo-se por tabela a criminalização da homofobia. 
Na Figura 8, nota-se que os homossexuais "masculinos" que participam da parada goianiense são mais sensíveis à discriminação, sendo o local de trabalho recorrentemente citado tanto pelos depoentes "masculinos", quanto pelas depoentes "femininas" (empregando-se aqui estes termos, masculino e feminino, relacionados ao registro civil das/dos depoentes). Veja-se que a casa igualmente aparece como local de discriminação, assim como a escola e outros espaços de acesso público. Talvez, por isso, quando conversamos com os/as participantes e perguntamos os motivos deles(as) integrarem a parada, vários(as) mencionaram o fato de "estar entre iguais" e aí não sofrerem discriminação.

Figura 8 - Discriminação em virtude de sua orientação sexual (Goiânia, 2010-2011, público LGBT)

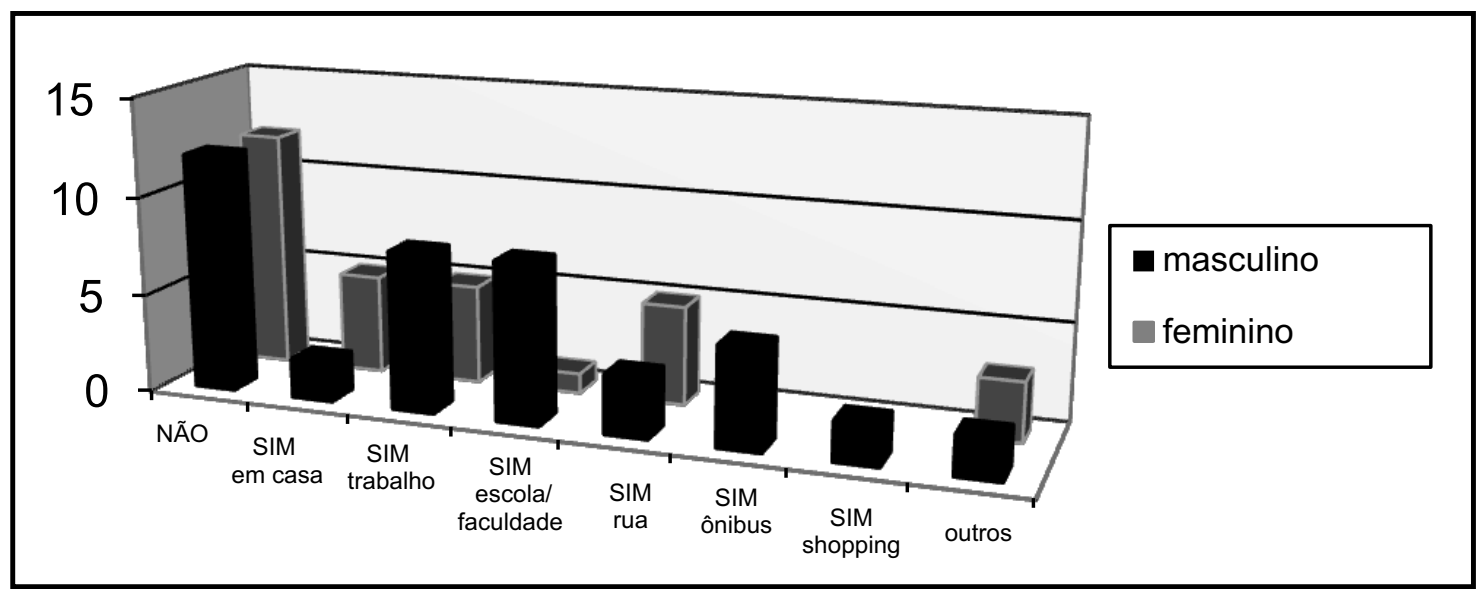

Todavia, não convém supor que entre o próprio público LGBT não haja discriminação. Assim, às vezes, travestis, transexuais e "pintosas" (homossexuais masculinos muito afeminados), bem como as lésbicas masculinizadas (pejorativamente chamadas de caminhoneiras ou xumas - inversão fonética de "macho") são discriminadas(os) por aqueles(as) que se julgam "discretos"(as) e "fora do meio" o(a)s quais, quando muito, acompanham com certo distanciamento a parada e com um olhar blasé. Por outro lado, os(as) "assumidos"(as) também costumam discriminar esses(as) que são tidos como "enrustidos"(as) ou "mal resolvidos" e ainda há outras nuances de discriminação referentes aos comportamentos sexuais.

Outro ponto que gostaríamos de levantar neste artigo, em referência às territorialidades produzidas na parada LGBT, baseados na realidade goianiense, diz respeito às descontinuidades horizontais e verticais relacionadas à disposição dos trios elétricos, ou simplesmente trios como são chamados.

Os trios elétricos são essenciais nas paradas LGBTs e, ao contrário do que ocorre nas suas funções originais, a música nacional-carnavalesca está ausente, sendo substituída pela internacional-dance. Os trios elétricos são contratados por entidades relacionadas ao movimento LGBT e boates para este público existentes na cidade, mas já houve edições em que uma sauna gay goianiense disponibilizasse um trio. Algumas personagens se 
destacam no alto dos trios, principalmente drag queens e gogoboys, que são bastante procurados por participantes que querem tirar fotos ao seu lado, já outros parecem desdenhá-los; de qualquer forma, ambas as atitudes confirmam a centralidade dos trios e de quem tem acesso a eles e os ratificam como microterritórios na festa.

Os trios estabelecem tanto descontinuidades horizontais quanto verticais nas territorialidades da parada, conforme dissemos, já que atraem públicos diferenciados, no tocante às horizontalidades, e têm seu acesso restrito, no que se refere às verticalidades.

A parada é iniciada com o(s) trio(s) elétrico(s) das ONGs e entidades organizadoras. $\mathrm{O}$ acesso a este(s) trio(s) é franqueado a convidados, no que diz respeito à verticalidade, sendo pouco acompanhados pelos participantes, pois em geral são menos decorados e têm som menos potente que os das boates.

Além do(s) trio(s) dos organizadores, em Goiânia, há os trios de boates e bares GLS, os quais possuem maior concorrência de público. Esses trios contratam DJs de outros estados, são mais decorados e têm maior potência de som. O trio de certa boate, particularmente, é o mais seguido, conferindo certo status aos que o seguem no chão como suposto frequentador desta boate, considerada a melhor da cidade.

$\mathrm{O}$ acesso ao interior desses trios de boates e bares, além de permitido aos convidados, é comercializado, sendo o controle exercido por pulseirinhas que são vendidas antes ou durante a parada, ratificando também na verticalidade um status diferenciado aos seus integrantes. A decoração dos trios é feita, amiúde, com as cores do arco-íris, que estão ainda presentes nas fantasias, adereços e nos produtos comercializados por camelôs e ambulantes na concentração da parada. $\mathrm{O}$ arco-íris torna-se, assim, um referencial simbólico de que a cidade é, naquele momento, palco da diversidade LGBT, sendo apontado pelas(os) participantes como o principal símbolo da parada.

Além do arco-íris, a parada permite a demonstração de identidades territoriais na apresentação do próprio corpo. Aqui cabem as palavras de Ladrière que, inspirado em Merleau-Ponty, comenta:

... Não devemos esquecer que a expressão é essencialmente corporal (...) Quando nos exprimimos, apenas ativamos uma possibilidade de nosso próprio corpo. O que significa que o corpo é antes de tudo poder expressivo...

... O corpo é o lugar de nossa comunicação com os outros e de nossa permuta com as coisas. Digamos mais simplesmente ainda: ele é nossa presença ao mundo, isto é, nossa abertura às coisas, ao espaço, aos outros, à cultura e à história; não de um modo intelectual (...), mas de uma maneira concreta, situada, enraizada, porque o corpo é precisamente isso, a união em rigor impensável, da situação de fato, puramente contingente e de um movimento que infinitamente a ultrapassa... (1979, p. 173-176)

Na parada LGBT, esse poder expressivo do corpo revela desejos de mudança, desejos de libertação e desejos de desejos. A corporeidade controlada por normas e costumes sociais na antifesta é substituída por outra transgressora na festa, na qual, entre outras possibilidades, se expõe o que antes era íntimo, se dá vazão à androginia e deixa-se levar pelo hedonismo. Pelo corpo, no contexto da parada, circulam significações de 
proximidades diversas e emergem relações espaciais que transcendem aquele instante. Tais relações e significações constituem-se a partir de compreensões de si mesmo como gay, lésbica, transexual, heterossexual etc. que já implicam também a compreensão do outro co-presente, ainda que isto esteja velado na fantasia da festa. Olhares e atenções são atraídos e a maioria procura mesmo exibir-se. Caras e bocas, peitos e peitorais, pernas e bundas, "malas" (genitália masculina na linguagem popular do/as participantes) e "xecas" (genitália feminina na linguagem popular do/as participantes) sobressaem-se no calor e no fim da estação seca goianiense.

\section{CONSIDERAÇÕES FINAIS}

A parada LGBT goianiense constitui-se como uma festa popular que atrai não só LGBTs, mas também participantes heterossexuais que buscam compartilhar desta situação ritualística de crise das diferenças. Nota-se, entretanto, que esta crise é parcial, o que se revela, entre outros aspectos, na sua circunscrição espacial em poucas ruas do centro da cidade.

Ressaltou-se ainda que a espacialidade da festa, conformada na concentração, percurso e dispersão, permite que territorialidades sejam produzidas pelos atores aí existentes e encenem diversidades que, na cotidianidade, estão restritas ou excluídas do palco urbano. Porém, na festa, estas territorialidades tornam-se estruturantes. Dois vetores principais orientam essas territorialidades, tendo como epicentro os trios elétricos: um vertical e outro horizontal, sendo que, em ambos, determinados elementos simbólicos indicam a existência da festa e identidades territoriais, nas quais não pode ser relegada a corporeidade dos participantes co-presentes.

\section{REFERÊNCIAS}

BELL, David (Entrevista). In: SILVA, Joseli Maria, VIEIRA, Paulo Jorge. "Fucking" geografia: entrevista com David Bell. Revista Latino-americana de Geografia e Gênero, Ponta Grossa, v. 1, n. 2, p. 318-325, ago. / dez. 2010.

BEIJAÇO gay em shopping paulista. Disponível em: <http://www1.folha.uol.com.br/folha/cotidiano/ ult95u79567.shtml> Acesso em: 12 fev. 2012.

ARISTÓTELES. A política. Rio de Janeiro: Ediouro, [1997?].

BÍBLIA SAGRADA. Disponível em: <http:/ / www.bibliaonline.com.br>. Acesso em: 8 fev. 2012.

CAMPOS, Ellwes Colle de. Religião e homossexualidade: ícones religiosos na Parada do Orgulho Gay do Distrito Federal. Dissertação (Mestrado em Ciências da Religião). Goiânia, UCG, 2006.

CONTRATO para locação de Trios na XIV Parada do Orgulho LGBT de Goiânia 2010. Disponível em: <http://paradagoias.blogspot.com/2010/08/regulamento-dos-trios-eletricos.html> Acesso em: 14 abr. 2010.

DAMATTA, Roberto. O que faz o Brasil, Brasil? 9. ed. Rio de Janeiro: Rocco, 1998.

DURKHEIM, Emile. Formas elementares da vida religiosa: o sistema totêmico na Austrália. São Paulo: Paulinas, 1989. 
EDIR Macedo da igreja Universal exorciza jovem homossexual. Disponível em: <http://www.youtube. com/watch?v=fRKsAv51gd8>. Acesso em: 8 fev. 2012.

FOTOS - II Parada do Orgulho Gay de Goiânia. Disponível em: <http:/ / www.midiaindependente.org/ pt/blue/2004/06/284567.shtml>. Acesso em: 8 fev. 2012.

GAYS protestam contra shopping. Disponível em: <http://www.ohoje.com.br/cidades/20-08-2006-gaysprotestam-contra-shopping/>. Acesso em: 12 fev. 2012.

GIRARD, René. A violência e o sagrado. 2. ed, São Paulo: Universidade Estadual Paulista, 1990.

GOIÂNIA tem II Parada do Orgulho Gay. Disponível em: <http://www.aids.gov.br/noticia/goianiatem-ii-parada-do-orgulho-gay>. Acesso em: 12 fev. 2012.

DICIONÁRIO Houaiss on-line. Disponível em: <http:/ / biblioteca.uol.com.br/>. Acesso em: 12 fev. 2012.

LADRIÈRE, Jean. Vida social e destinação. São Paulo: Convívio, 1979.

MAGNANI, José Guilherme Cantor. Cidade universitária: patrimônio e identidade. Disponível em: <http:/ / www.n-a-u.org/magnani-cid-universit.html>. Acesso em: 8 fev. 2012.

MELO, Marcos Ribeiro de. Etiqueta em ambientes de pegação: fronteiras e normalização no movimento homossexual brasileiro. In: REUNIÓN DE ANTROPOLOGÍA DEL MERCOSUR (RAM), 8. Anais... "Diversidad y poder en América Latina", 2009. Buenos Aires. RAM 2009.

SACK, Robert D. O significado de territorialidade. In: DIAS, Leila Christina, FERRARI, Maristela. Territorialidades humanas e redes sociais. Florianópolis: Insular, 2011, p. 63-90.

Recebido em 14/01/2012

Aceito para publicação em 22/03/ 2012 